\title{
Common Bile Duct Elongation and Obstruction Secondary to Duodenal Intussusception and Ampullary Adenoma in a Patient with Pancreas Divisum
}

\author{
Arturo Torices Dardon*, MD, Anthony Dakwar, MD, Pierre F Saldinger, MD, FACS and Kaumudi \\ Somnay, MD
}

Weill Cornell Medical College, New York Presbyterian Queens, New York, USA

\section{Introduction}

Small bowel intussusception is an uncommon condition with cases of duodenoduodenal intussusception. (DDI) being exceptionally rare. DDI is very unusual due to the fixed position of the duodenum within the retroperitoneum. In this case, the presence of an ampullary mass caused DDI with sub mucosal elongation of the common bile duct and obstructive jaundice in a patient with pancreas divisum.

\section{Methods}

65-year-old female who underwent ERCP for Jaundice, abnormal liver function test, acquired bile duct dilation and Cholangitis like symptoms. She was found to have ampullary mass causing intussusception and Pancreas Divisum (Figure 1).

The large tumor was identified in the third part of the

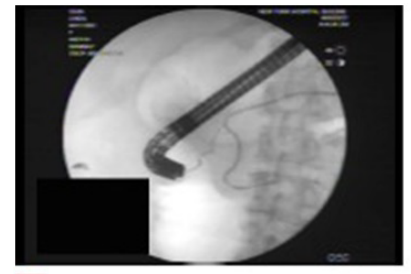

1

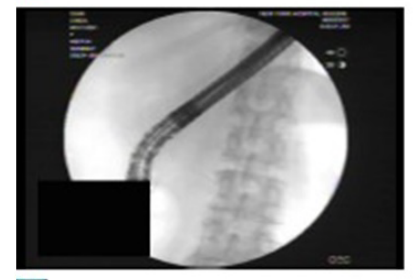

[5]

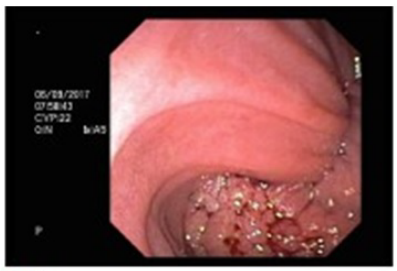

目

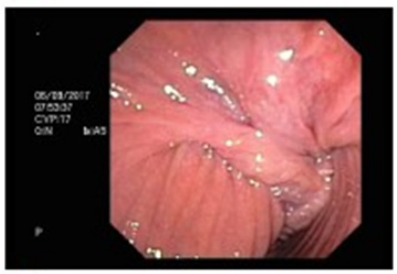

6

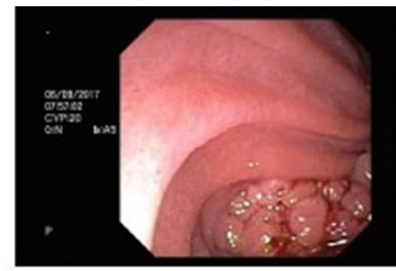

3

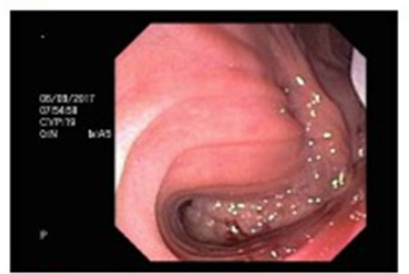

7

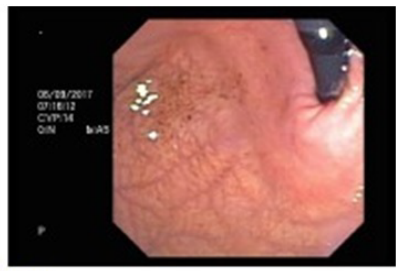

(4)

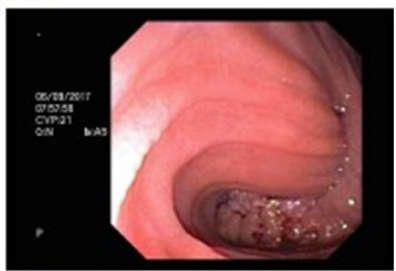

8

Figure 1: ERCP. An incomplete pancreas divisum was identified. Bile duct opening was not noted at this ampulla. Found a separate bile duct opening, noted to be displaced distally. Also an irregular mass was noted at this ampulla. 
a)

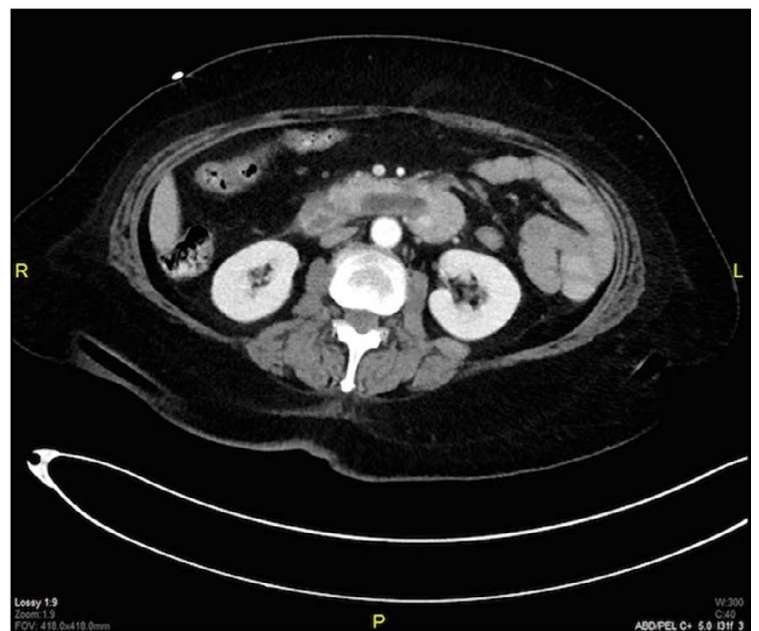

b)

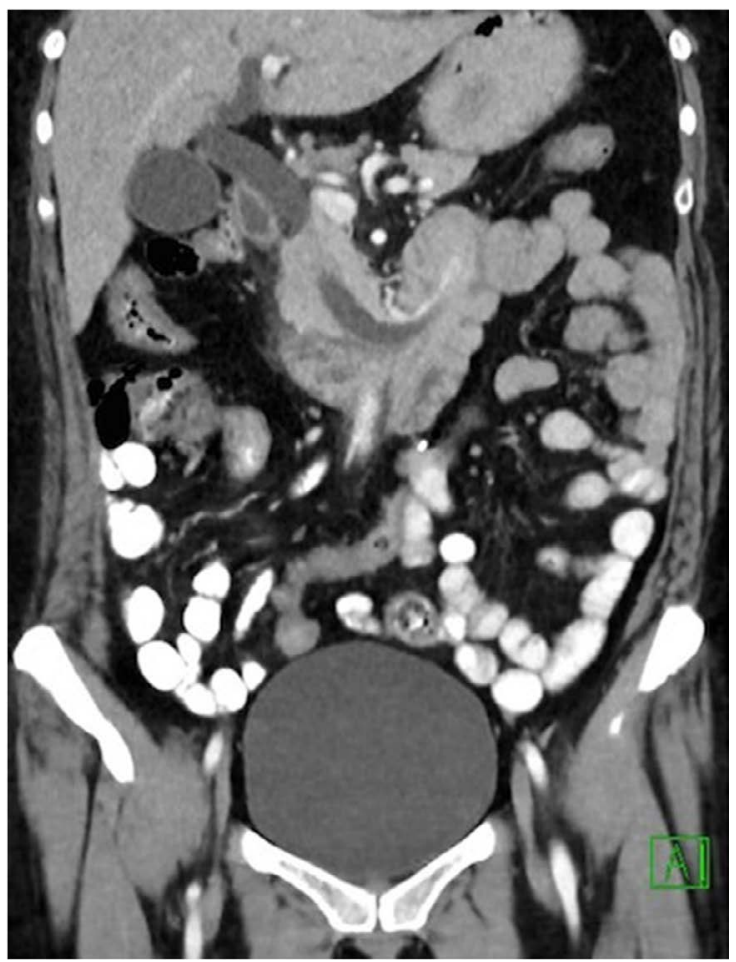

Figure 2: a,b) Moderate intrahepatic ductal dilatation with dilatation of the CBD measuring $1.2 \mathrm{~cm}$ which extends to the left of the midline where there is suggestion of duodenaljejunal or duodenal-duodenal intussusception.

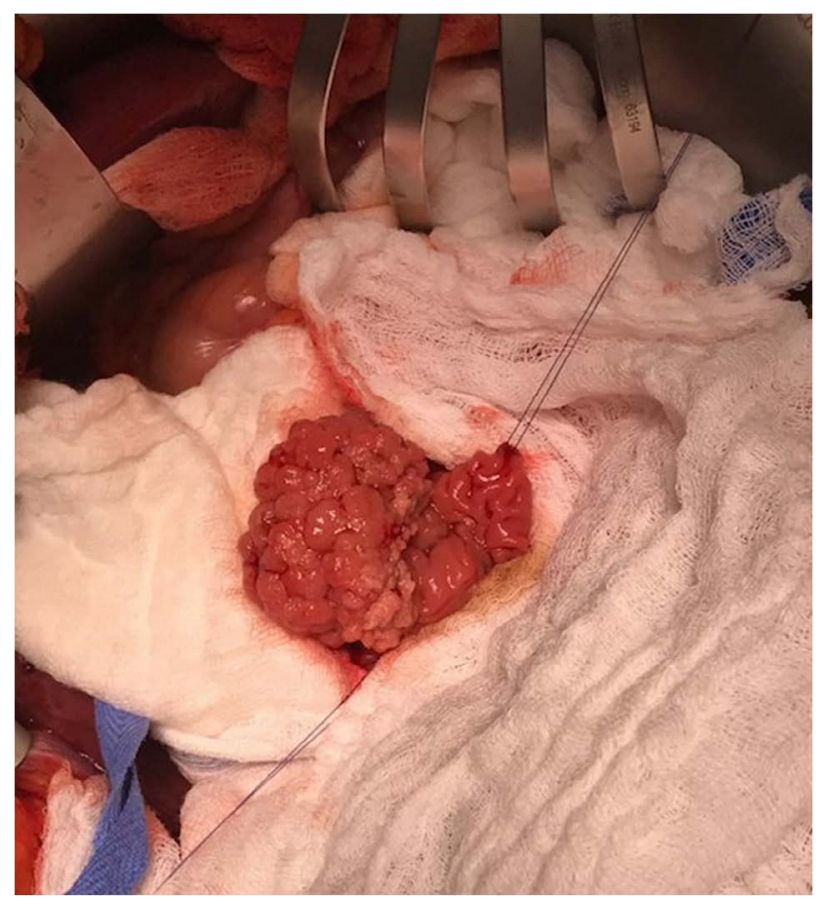

Figure 3: Pathology Report. Peri-ampulla mass, resection: Villous adenoma with microscopic superficial foci of high grade dysplasia, completely excised. Stalk margin is negative for adenomatous change and negative for dysplasia.

duodenum. CT scan and MRI revealed that there is an intussusception, with the elongated common bile duct entering the duodenum to the left of the midline (Figure 2).

\section{Results}

The tumor was palpated close to the Ligament of Treitz at exploration. The patient underwent Exploratory laparotomy, cholecystectomy, exploration of common bile duct, excision of ampulla of Vater with reimplantation of common bile duct. Due to the presence of Pancreas Divisum, no pancreatic duct was encountered within the ampulla, which was advantageous (Figure 3).

\section{Conclusion}

This is to our knowledge the first description of a duodenal intususception causing an elongation of the bile duct to the left of the midline.

DOI: $10.36959 / 879 / 374$ 